В статье рассматриваются проблемы инвестиционной привлекательности российских организаций корпоративного уровня, политико-правовые, экономические и социальные факторы внешней среды в Российской Федерации. Исследуются внутренняя среда российских компаний и особенности инвестиционной деятельности российских и иностранных компаний. Анализируются принципы и рекомендации международных организаций экономического сотрудничества и развития, европейских ассоциаций фондовых дилеров и европейских акционеров, показаны особенности их применения в российских компаниях. Оценивается степень соответствия системы корпоративного управления и корпоративной социальной ответственности российских компаний принципам справедливости, ответственности, подотчетности и прозрачности. Рассмотрены процессы формирования корпоративных стратегий российских компаний, практика формирования вертикально-интегрированных компаний, горизонтальных и конгломератных интеграционных процессов. По результатам исследований инвестиционного климата и экономической устойчивости российских компаний авторами даны рекомендации для усиления связей компаний с инвесторами на основе развития системы корпоративного управления в части стандартизации управленческой практики, консолидации отчетности в соответствии с международными стандартами и др. Реформирование системы корпоративного управления в компании необходимо с целью повышения предсказуемости компании в глазах инвесторов и снижения риска в инвестиционных вложениях.

Ключеbые слова: инвестиционная политика, социальные аспекты инвестиций, принципы управления компанией, корпоративные стратегии.

\title{
UPGRADING THE SYSTEM OF CORPORATE MANAGEMENT IN COMPANY IN ORDER TO RAISE ITS ECONOMIC SUSTAINABILITY AND INVESTMENT APPEAL
}

\author{
Nina F. Lozik, Alexander Y. Anisimov, Artur A. Panasyuk \\ Institute of World Civilizations, Moscow, Russia
}

The article studies the issue of investment appeal of Russian corporate organizations, political, legal, economic and social factors of external environment in the Russian Federation. It analyzes the internal environment of Russian companies and specific features of investment activity of Russian and foreign companies, as well as principles and recommendations of international organizations of economic cooperation and development, European associations of stock brokers and European shareholders and shows their potential use in Russian companies. The authors estimate the degree of compliance of the system of corporate management and corporate social responsibility in Russian companies with principles of justice, responsibility, accounting and transparency. They study processes of developing corporate strategies in Russian companies, practice of building vertically-integrated companies, horizontal and conglomerate integration processes. As a result of researching the investment climate and economic sustainability of Russian companies the authors prepared recommendations aimed at strengthening the ties between companies and investors on the basis of the system of corporate management in the aspect of managerial practice 
standardization, accounting consolidation in accordance with international standards and others. Restructuring the system of corporate management in company is essential in order to improve the company predictability for investors and to cut risks in investment.

Keywords: investment policy, social aspects of investment, principles of company management, corporate strategies.

B последние годы российские промышленные предприятия испытывают острую потребность в инвестициях. Российская промышленность попрежнему значительную долю прибыли получает от предприятий сырьевого сектора и экспортно ориентированных отраслей, однако спрос на капитал со стороны этого сектора остается высоким [7]. Можно выделить несколько основных причин (факторов), влияющих на эти потребности:

- падение иен на нефть, обусловленное целым комплексом факторов, включая ускоренный переход личного и коммерческого транспорта на альтернативные источники (в том числе электроэнергию), технологические достижения в области нефтедобычи, расширение масштабов использования сжиженного природного газа и географии его транспортировки;

- санкции со стороны США и ряда европейских стран, выразившиеся в существенном сокращении возможностей по привлечению долгового финансирования и снижению числа потенциальных инвесторов в долевое участие в российских проектах и месторождениях;

- рост капиталоемкости новых проектов, вызванный удорожанием технологий, общим снижением доступности ресурсов для извлечения (глубина залегания, наличие транспортной инфраструктуры, зоны холода);

- преимущества от интеграции и приобретения новых активов, требующих достаточно больших свободных средств.

Корпорации, чьи акции котируются на фондовом рынке, получают преимущества в процессе расширения бизнес-процессов. Как показывает практика, при сделках по слиянию или поглощению, когда производится оплата приобретаемого актива собственными акциями, прослеживается четкая зависимость между фактическими за- тратами компании на покупку и уровнем ее оцененности, а именно, чем выше компания оценена рынком, тем ниже ее расходы на развитие бизнеса [3].

Вышеперечисленные факторы сильно сократили уровни оценки российских компаний, имеющих котировки на открытом рынке как в виде акций, так и в виде производных инструментов (депозитарных расписок). Одним из путей повышения относительной стоимости российских активов и, как следствие, конкурентоспособности российского бизнеса на глобальной арене является рост качества корпоративного управления.

Процесс привлечения как заемного (в виде кредитов, размещения векселей и облигаций), так и долевого (выпуск дополнительных акций) капитала предъявляет значительные требования к системе корпоративного управления компании. Компании корпоративного уровня, имеющие публично торгуемые акции или долговые бумаги, должны соблюдать целый ряд юридических и процедурных формальностей, предъявляемых организациям такого уровня [1].

Принципы и рекомендации, которыми руководствуются в своей деятельности организации корпоративного уровня, разработаны рядом системообразующих международных организаций, в числе которых:

- Организация экономического сотрудничества и развития (ОЭСР);

- Конфедерация ассоциаций европейских акционеров;

- Международная сеть корпоративного управления;

- Европейская ассоциация фондовых дилеров.

За последние 10 лет в 40 странах принято более 100 кодексов корпоративного управления. Основное внимание в них уделяется системе корпоративного управ- 
ления, роли советов директоров в компаниях, взаимодействию руководства компаний с органами государственной власти, ответственными за выработку политики в области корпоративного управления.

Принципы ОЭСР затрагивают все направления системы корпоративного управления: права акционеров, роль заинтересованных лиц, практику деятельности совета директоров и раскрытие информации. Они приняты во многих странах мира в качестве основополагающего документа при разработке законодательства и национальных кодексов корпоративного управления, в том числе и российского Кодекса корпоративного поведения [2]

При формировании системы корпоративного управления в России, в частности при разработке Кодексов корпоративного управления 2002 и 2014 гг., а также в процессе дальнейшего совершенствования корпоративного законодательства отечественными специалистами были учтены рекомендации ОЭСР.

Корпоративное управление и его совершенствование на современном этапе рыночных отношений в России продолжают оставаться одним из самых обсуждаемых аспектов практической деятельности коммерческих структур и существенным фактором их динамичного развития.

Повышенное внимание к корпоративному управлению вызвано тем неоспоримым фактом, что от его качества в значительной степени зависит рост стоимости акционерного капитала. По данным Всемирного банка, только за счет роста качества корпоративного управления общая капитализация российского рынка акций могла бы возрасти с 600 млрд до 1,3 трлн долларов.

Финансовый кризис 2008 г. стал еще одним сигналом для дальнейшего совершенствования системы корпоративного управления в России. Именно он поставил вопрос об ответственном поведении менеджмента и руководства компаний, формировании системы стимулирования (incentives) в сфере корпоративного управ- ления. Усовершенствованная система корпоративного управления повысила роль институциональных инвесторов, предъявила более высокие требования к разработке стратегий, технологиям продаж, усложнению инвестиционных цепочек. Повысилась роль финансовых структур, таких как публичные фондовые рынки и различные посредники. Доработанная система корпоративного управления внесла коррективы в области реализации прав акционеров и защиты этих прав.

Проект новых принципов корпоративного управления России был сформирован в течение 2014-2015 гг., утвержден Советом ОЭСР и одобрен на саммите G20, что значительно повысило статус России.

В основе концепции корпоративного управления ОЭСР лежат четыре ключевых принципа:

1. Справедливость. Система корпоративного управления должна защищать права акционеров и обеспечивать равное отношение ко всем акционерам, в том числе миноритарным и иностранным. Все акционеры должны иметь доступ к эффективным средствам защиты в случае нарушения их прав. Права и интересы миноритарных акционеров не должны ущемляться.

2. Ответственность. Система корпоративного управления должна признавать предусмотренные законом права заинтересованных лиц и способствовать активному сотрудничеству между компаниями и заинтересованными лицами в целях создания рабочих мест, обеспечения благосостояния и устойчивости здоровых с финансовой точки зрения компаний. Термин sustainable development (устойчивое развитие) лег в основу отдельной системы отчетности, подготавливаемой ведущими публичными компаниями развитых стран.

3. Прозрачность. Система корпоративного управления должна обеспечивать своевременное и одновременное (не имеющее преимущественных адресатов) раскрытие достоверной информации по всем существенным вопросам, касающимся компании, в том числе о ее финансовом положе- 
нии, результатах деятельности, структуре собственности и управления.

4. Подотчетность. Система корпоративного управления должна обеспечивать стратегическое руководство компанией, эффективный контроль за управляющими со стороны совета директоров, а также подотчетность совета директоров акционерам.

На рис. 1 приведены основные принципы корпоративного управления, рекомендованные ОЭСР.

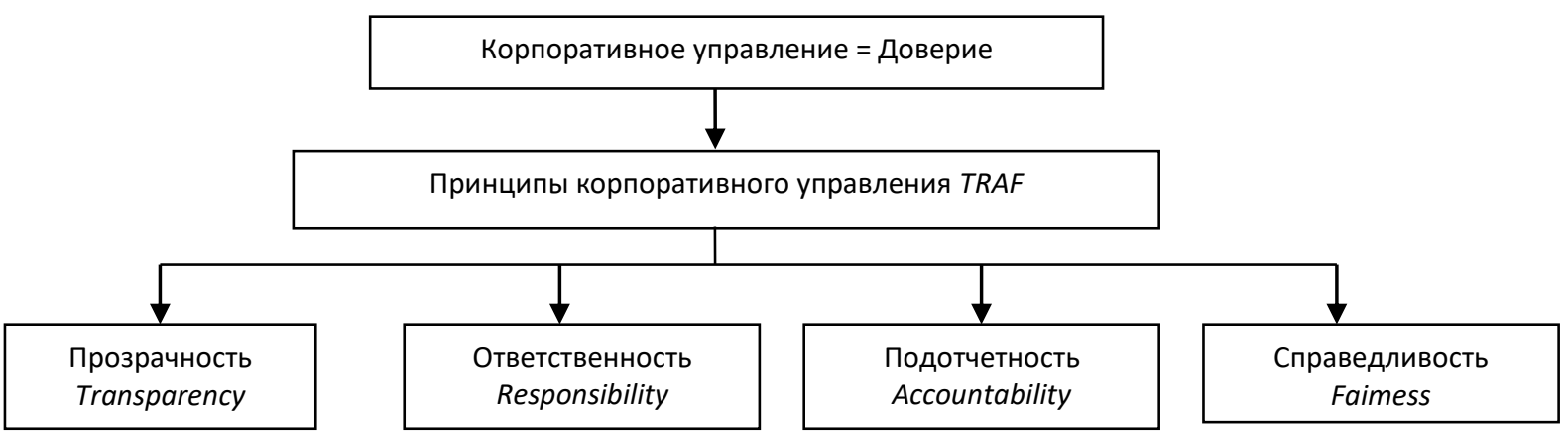

Рис. 1. Основные принципы корпоративного управления

Главным условием для удачного выхода на рынки капитала является прозрачность системы корпоративного менеджмента. Непрозрачность деятельности наносит предприятию вред, который в современном мире имеет не умозрительный характер, а выражается в поддающихся оценке показателях кредитного рейтинга, ликвидности ценных бумаг и уровне доступа со стороны инвесторов.

Таким образом, реформирование системы корпоративного управления в российских компаниях - одна из важнейших задач практического менеджмента. С очень большими допущениями можно даже предпринять попытку стоимостной оценки вреда, наносимого непрозрачностью, либо выгоды от установления прогрессивных практик корпоративного менеджмента [1].

Степень раскрытия информации и комплекс мероприятий по связям с инвесторами и организациями управления бизнесом относятся к четырем компонентам (наряду со страховыми и отраслевыми рисками, экономическими и финансовыми показателями), определяющим рейтинг, выставляемый как международными (Standard and Poors, Moody's, Fitch), так и российскими (Национальное рейтинговое агентство, «Эксперт РА», ЗАО «Анализ, Консультации и Маркетинг», «РусРейтинг») агентствами.

При определении приемлемого уровня доходности долговых бумаг инвесторы ориентируются на кредитный рейтинг эмитента, отношения между рейтингами заемщиков, формирующими спред (разницу, премию) в доходности выпускаемых ими финансовых инструментов. Низкий кредитный рейтинг приводит к росту затрат компании на обслуживание заемного капитала [5].

Недостаточно высокая ликвидность ценных бумаг становится среди прочего сдерживающим фактором для компании в процессе интеграции или приобретения активов. Одним из ярких примеров влияния низкой ликвидности на оценку бизнеса является историческая стоимость акций ПАО «ТНК» (одной из крупнейших нефтяных компаний) до момента ее приобретения ПАО «Роснефть». ПАО «ТНК», как и многие другие вертикально интегрированные нефтяные компании (ВИНК), неоднократно проводили обмен собственных акций на акции дочерних компаний с целью увеличения доли холдинга до $100 \%$.

Одним из препятствий для высокой 
оценки рынком стала неясность перспектив акций ПАО «ТНК», предлагавшихся для обмена, поскольку они не являлись ни потенциальным источником дивидендов, ни ликвидным финансовым инструментом, позволяющим выйти из рынка через свободную продажу. Центром прибыли и наиболее вероятным центром сделок по слиянию и поглощению была компания TNK International, головная структура всего бизнеса данной ВИНК [7].

Примером ограничения по спектру потенциальных инвесторов являются разнообразные индексы, служащие ориентиром для индексных фондов или критерием соответствия для институциональных инвесторов - пенсионных фондов, страховых компаний, фондов взаимных инвестиций (самый известный - Morgan Stanley Capital Index - MSCI). В MSCI допускаются компании, имеющие уровень free float (доля акций в свободном обращении) не менее $15 \%$, что исключает возможность полного контроля над компанией со стороны основного собственника (в течение целого ряда лет примером такого владения с долей 92\% была компания «Сибнефть», ныне ПАО «Газпромнефть») [4].

Можно выделить пять управленческих аспектов подготовки компании к выходу на рынки капитала: независимость менеджмента, принцип демократичности при формировании наблюдательных органов, информационная прозрачность, гласная долгосрочная стратегия и критерии ее оценки, формализованный алгоритм принятия решений.

Независимость менеджмента обеспечивает равные права всем группам акционеров, минимизирует управленческие риски и опасность несправедливого распределения экономических результатов. Основные требования - разделение постов президента, председателя правления и председателя совета директоров; основной акционер не вмешивается в оперативное управление компанией. Так минимизируется риск управления в интересах одного из собственников, а следовательно, и риск не- равномерного распределения финансового результата среди совладельцев фирмы: создания подконтрольных доминирующему акционеру сбытовых и/или закупочных компаний, вывода активов и их последующей аренды по завышенным ценам, создания долговой цепочки, состоящей из займов в аффилированных кредитных организациях и пр.

Демократичность принципов при формировании наблюдательного совета и совета директоров необходима для обеспечения плюрализма при принятии стратегических решений, нахождения консенсуса. Независимые директора - это либо представители мелких акционеров, либо отраслевые профессионалы, авторитетные специалисты. Следует отметить, что независимый совет директоров - это не только обязанность, но и право компании, а именно право на доступ к общественному, в том числе и мировому, отраслевому опыту, возможность использования образцовой практики в вопросах финансового менеджмента и подбора персонала, внедрение лучших технологических решений. Особого внимания заслуживает присутствие в наиболее прогрессивных советах директоров профессионалов из неродственных отраслей, что обеспечивает обмен интеллектуальным капиталом между секторами экономики.

Информационная прозрачность предполагает постоянную связь с общественностью, публикацию финансовой отчетности (регулярной, доступной, достоверной). Стратегические цели этой деятельности должны быть сформулированы и доведены до общественности. В современных условиях именно информационная прозрачность выходит на первый план, а точнее, ее частный аспект, имеющий в зарубежной практике название news flow (новостной поток) [3].

Подход, который нами условно обозначен как событийно ориентированный, состоит в следующем: при принятии инвестиционного решения инвестор действует рационально; основным фактором его ин- 
вестиционных предпочтений является наличие гарантированного потенциала получения дохода от финансового инструмента. Ключевыми становятся два показателя - потенциал роста и вероятность реализации этого потенциала.

В сущности, эти показатели представляют собой не что иное, как интерпретацию традиционных компонентов инвестиционного решения - доходности и риска. Однако когда мы говорим о потенциале, то вносим в его трактовку элементы вероятностного подхода, поскольку методологически потенциал роста для инструментов с плавающей доходностью или долевых инструментов является величиной прогностической.

Применительно к акциям речь идет о так называемых справедливых (целевых) ценах, о котировке, при которой капитализация компании соответствует ее фун- даментально обоснованной стоимости. Абстрагируясь от дискуссии о возможных методах определения этого показателя, возьмем за основу наиболее широко распространенный и доминирующий в современной экономической парадигме метод дисконтированных денежных потоков.

Классический вариант его применения предполагает построение финансовой модели компании, представляющей собой описание производственных, технологических и финансовых пропорций конкретной бизнес-модели, прогнозирование внешней конъюнктуры (цен на продукцию, рынок труда, капитала, основные статьи себестоимости) и определение будущих денежных потоков по ряду периодов.

На рис. 2 представлены основные составляющие системы корпоративного управления компании.

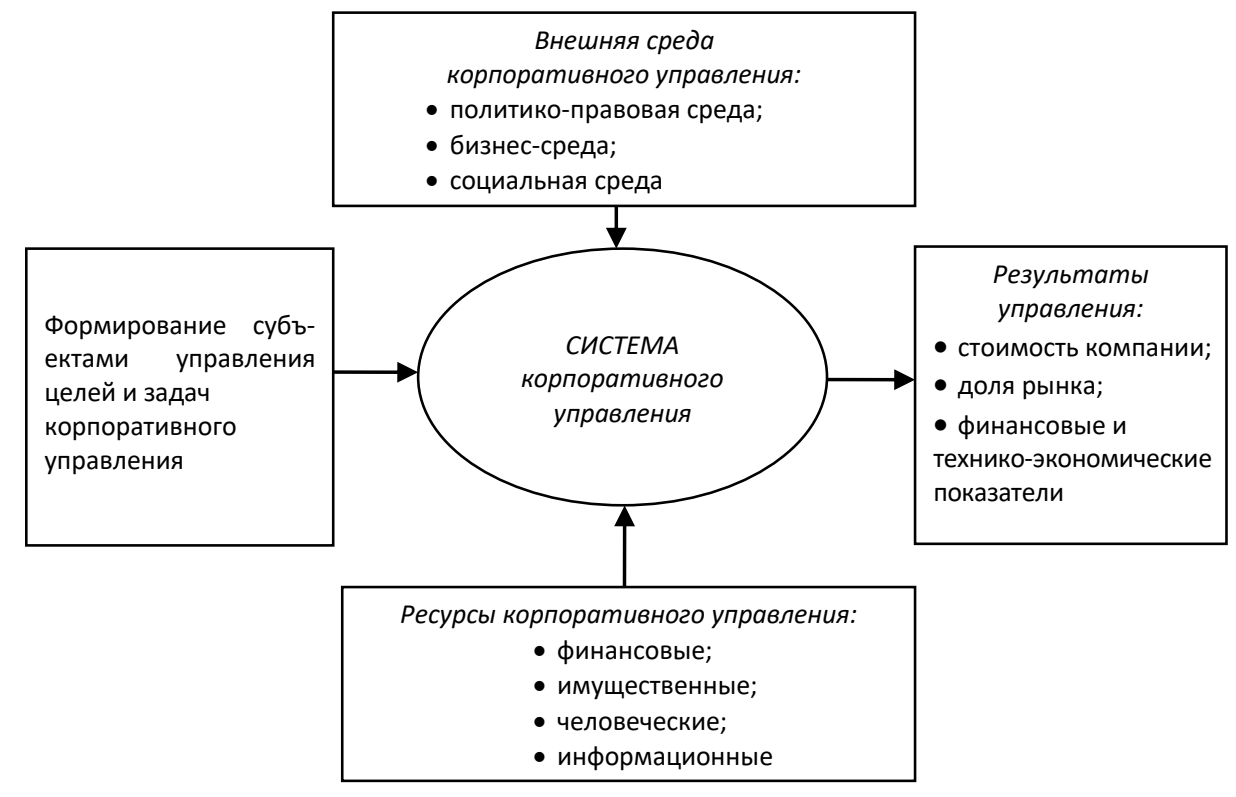

Рис. 2. Факторы системы корпоративного управления

Абсолютно необходимым является вариативный (или сценарный) анализ - подбор нескольких вариантов развития событий, который предоставляет возможность оценить зависимость справедливой цены, а значит, и вероятного поведения курса акций от отдельных факторов при условии, что изменение в справедливой цене под- талкивает участников рынка к перемене в отношении к данному инструменту. Его результатом является формирование спектра справедливых цен в диапазоне от пессимистического сценария до оптимистического. Создание сценариев по ряду показателей позволяет сформировать болышой набор целевых цен, причем количество их 
кратно возрастает при введении новых переменных в сценарный расчет.

Для инвестора принципиально важна ширина диапазона потенциальных цен. Психологически наиболее значима нижняя граница, но и большее рассеяние свидетельствует о крайней неопределенности данного инструмента для нужд инвестирования.

Стремясь к повышению собственной инвестиционной привлекательности, компания должна среди прочего повышать предсказуемость своего развития и, как следствие, сужать допустимые пределы колебания справедливых цен.

Повышение степени достоверности прогностических данных, закладываемых аналитиками при формировании собственных математических моделей, приводит чаще всего к сокращению используемых в них понижающих коэффициентов. Например, публикация ОАО «РИТЭК» в октябре 2002 г. собственной производственной программы позволила аналитикам инвестиционных и брокерских компаний повысить рекомендации по акциям
РИТЭК с 1,4-1,6 долларов до 1,9-2,4 долларов, в частности, в силу менее консервативных предположений относительно объемов добычи нефти в будущем.

До публикации официальной программы прогнозы аналитиков содержали поправочные коэффициенты, показывающие недоверие исследователей к планам, устно представленным руководством компании [9].

Реформирование системы корпоративного управления в компании необходимо с целью повышения предсказуемости компании в глазах инвесторов, а следовательно, снижения компоненты риска во вложениях. Надо отметить, что реформирование корпоративного управления - естественный эволюционный процесс на пути реструктуризации любых отраслей, в том числе промышленности.

Большинство крупных российских компаний в настоящее время объединены в корпоративные структуры.

Как следует из данных рис. 3, количество сделок с 2012 по 2018 г. возросло практически в два раза (в 1,95 раза).

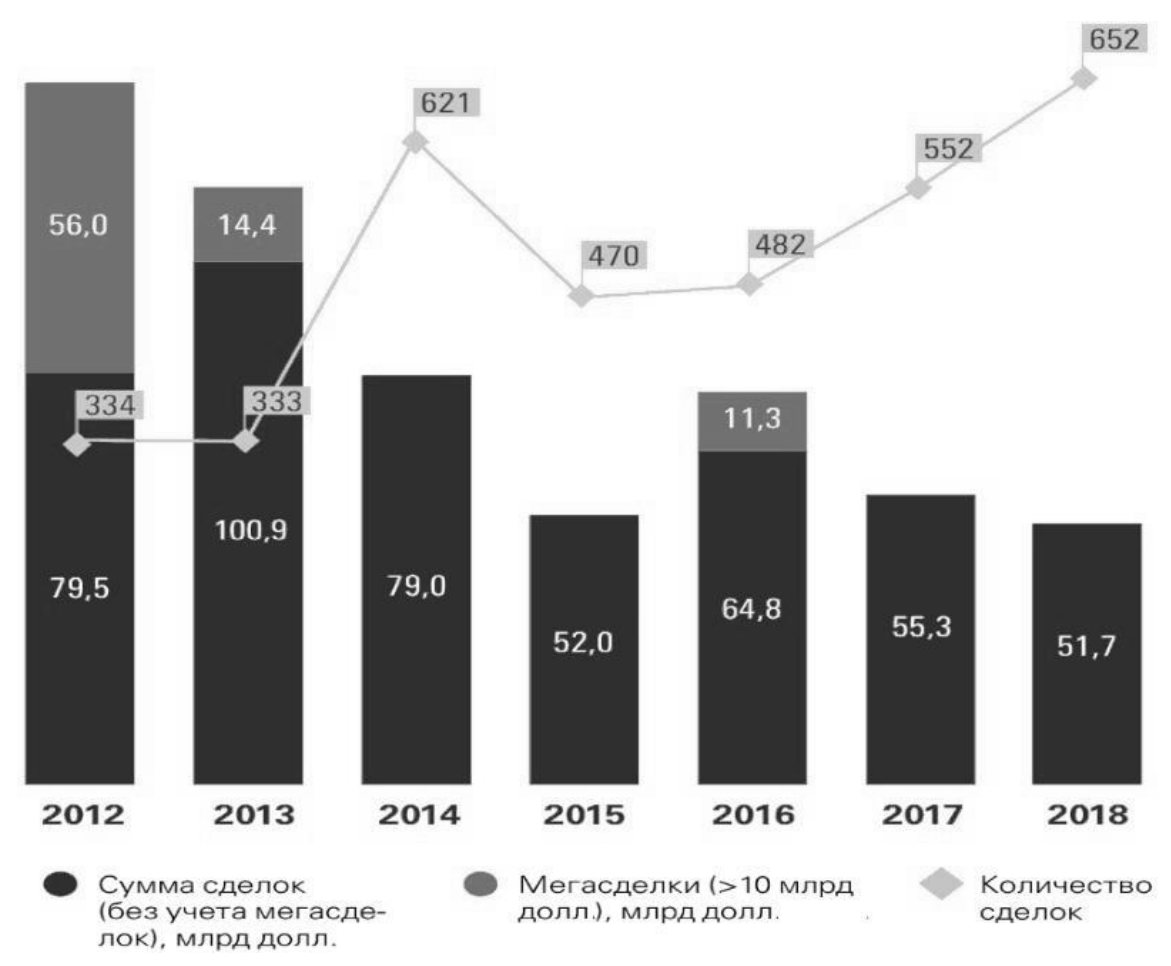

Рис. 3. Российский рынок слияний и поглощений (М\&A) с 2012 по 2018 г. 
Наибольший рост сделок по слиянию и поглощению (M\&A) произошел в секторах инноваций и технологий. Отраслевой раз- рез количества сделок М\&A в 2018 г. в сравнении с 2017 г. представлен на рис. 4.

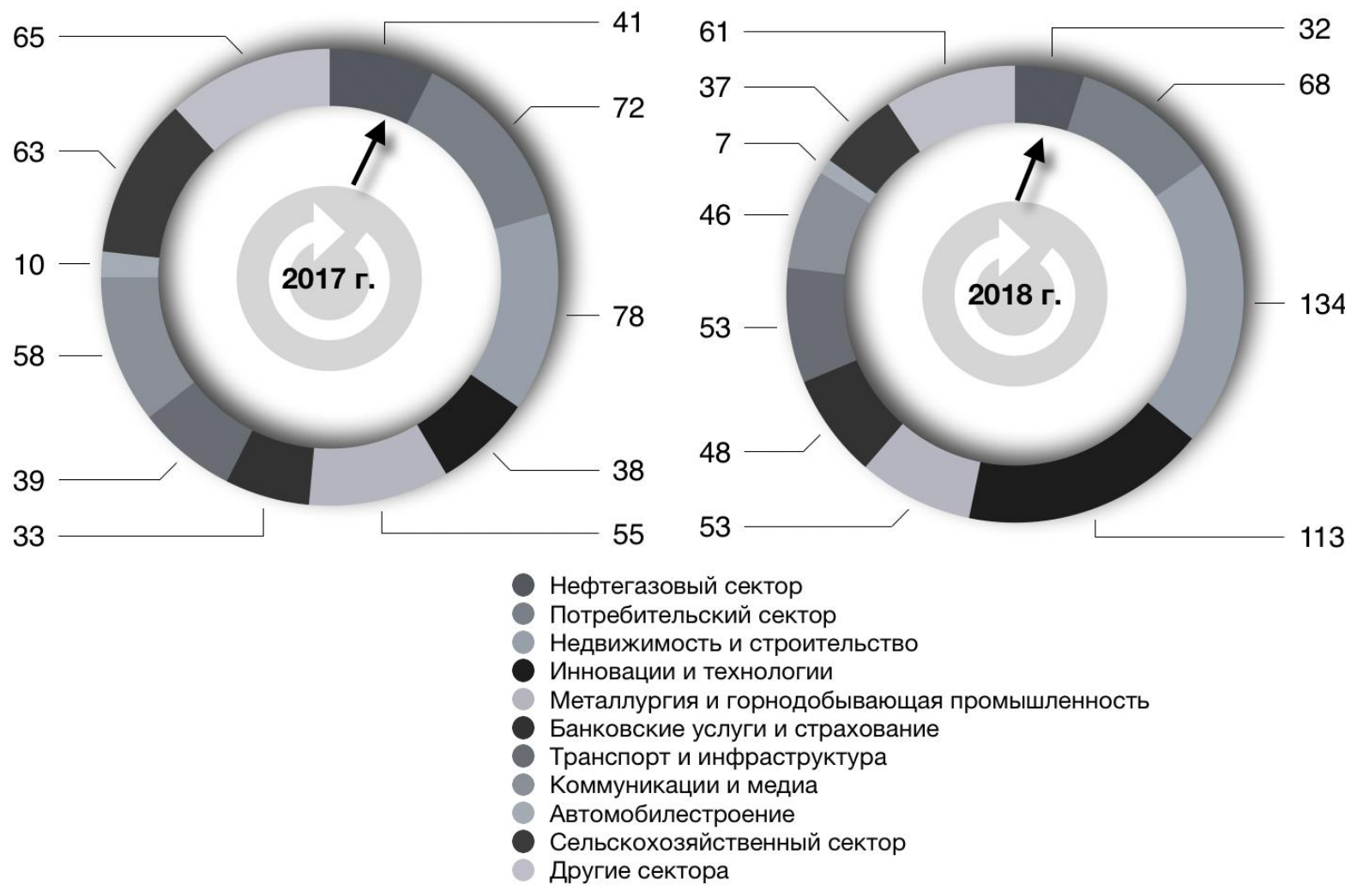

Рис. 4. Количество сделок М\&A по отраслям с 2017 по 2018 г.

Типологизация сделок российского ственном выражении представлена на рынка М\&А в стоимостном и количе- рис. 5.
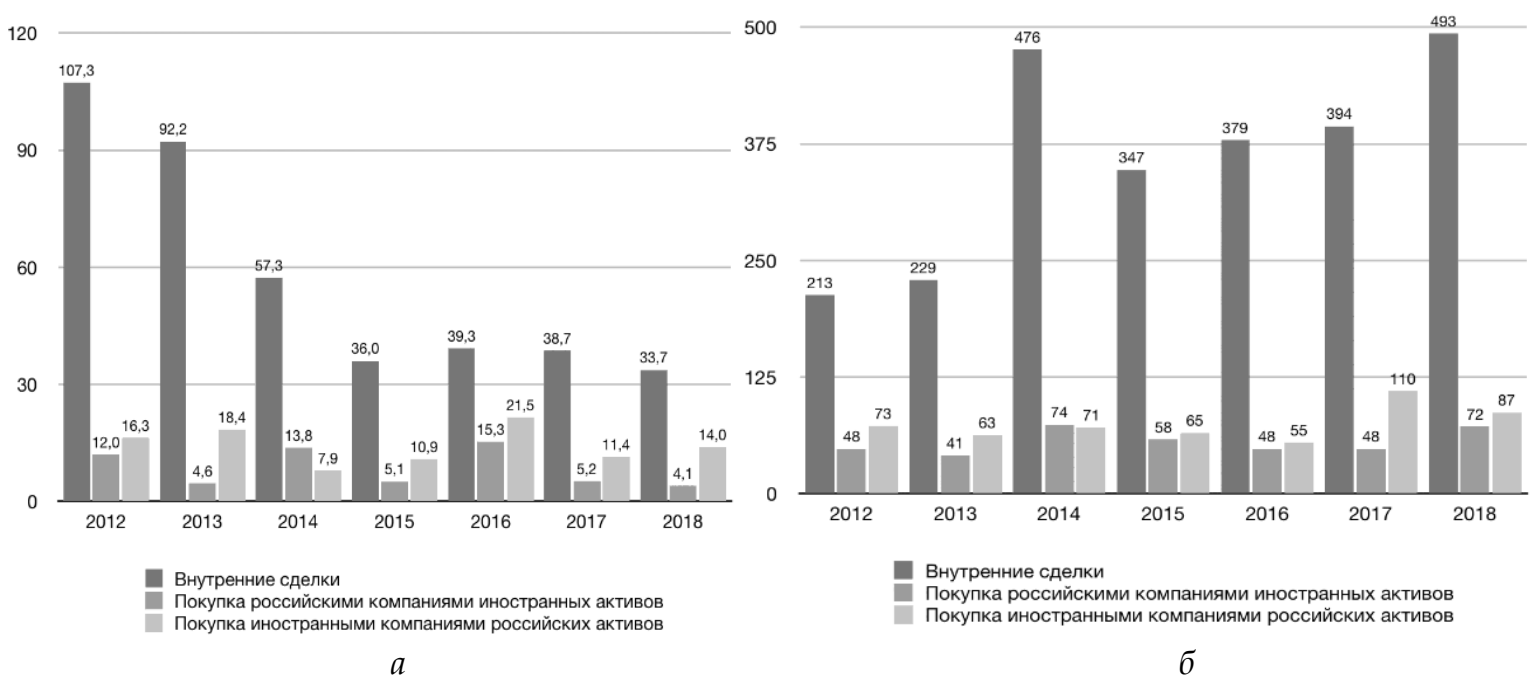

Рис. 5. Российский рынок М\&А по типам сделок в стоимостном (a) (млрд долл.) и количественном (б) выражении за период с 2012 по 2018 г. 
Одиночных компаний практически не осталось. Исключение составляют только крупные предприятия в таких отраслях, как машиностроение, лесопереработка, химическая промышленность, которые обладают самодостаточными замкнутыми производственными циклами. В 2018 г. преобладали локальные сделки M\&A как по объему, так и по количеству. В целом общий объем сделок в 2018 г. сократился на 23,4\% по сравнению с 2017 г. при несущественном снижении количества сделок на 3,6\%, что свидетельствует о снижении среднего размера сделки.
Основные драйверы активности М\&A в секторе металлургии и горнодобывающей промышленности за последние годы:

- реструктуризация долгов добывающих предприятий (актуальна для сделок среднего размера);

- перераспределение долей между существующими акционерами (актуально для крупных сделок).

На рис. 6 представлена динамика интеграционных процессов на российском рынке в металлургии и горнодобывающей промышленности.

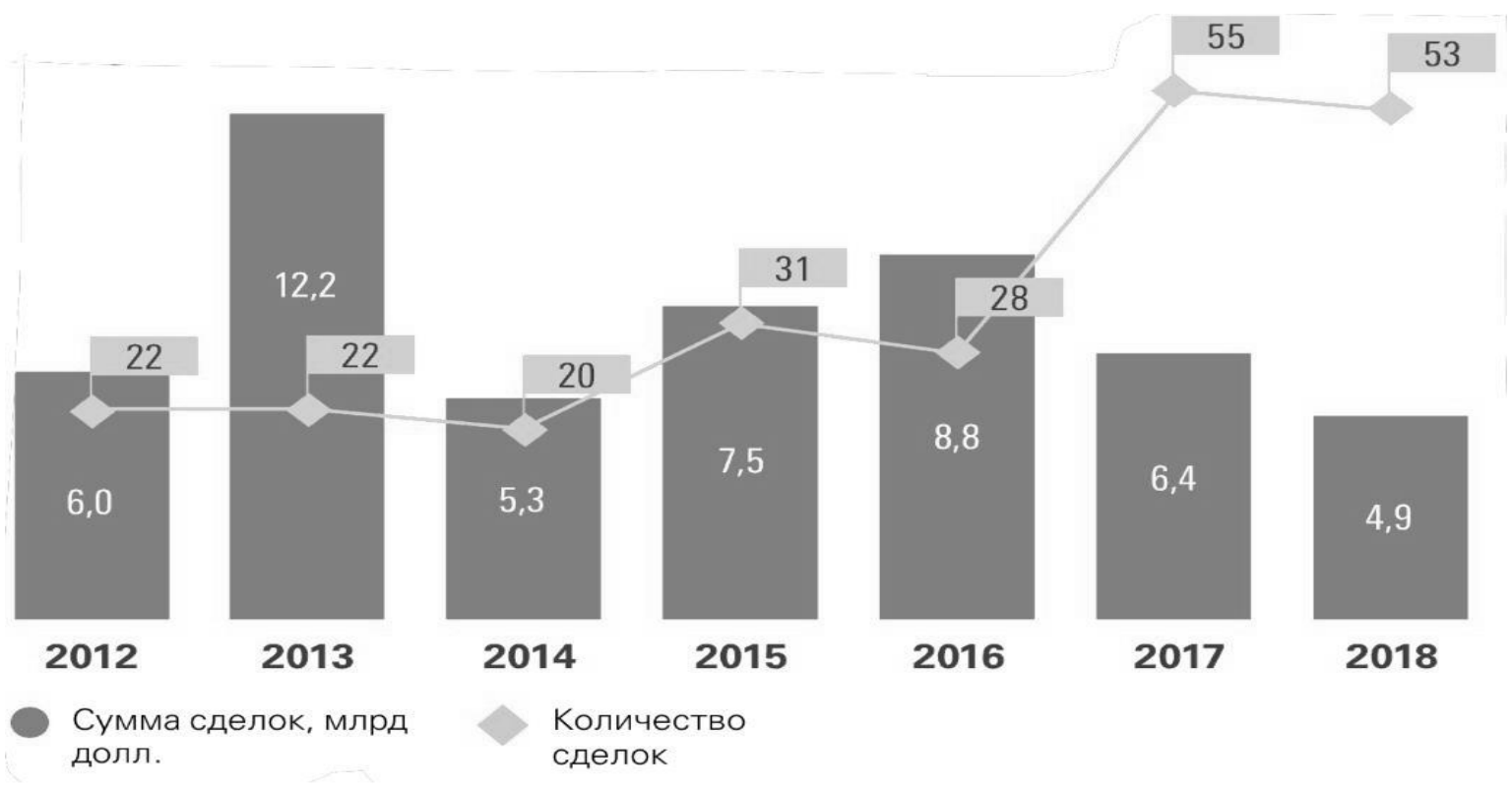

Рис. 6. Российский рынок М\&А в металлургии и горнодобывающей промышленности

Укрупнение российских компаний стало первым этапом преобразования отечественной промышленности. Наиболее частым мотивом для приобретения смежного производства была страховка от нестабильности поставок, ценового шантажа. Нестабильность поставок могла быть как умышленной (недружественное поведение новых владельцев приватизируемого предприятия), так и неумышленной (предприятие теряло управляемость и ввергалось в хаос по причине конфликтов собственников или региональных катаклизмов).

В такой ситуации руководство большинства промышленных компаний озаботилось скупкой производства родственного и технологически связанного профиля [6].

Сталелитейные компании («Северсталь», «Евразхолдинг») в подавляющем большинстве приобрели стабильные источники сырья (железные руды, коксующиеся угли), предприятия алюминиевой промышленности (ОАО «РУСАЛ» и ОАО 
«СУАЛ» - ныне единый холдинг) скупили глиноземные комбинаты. Крупнейшей объявленной сделкой 2018 г. стало приобретение Баимского медного месторождения, одного из крупнейших в мире, компанией KAZ Minerals за 900 млн долларов с оплатой денежными средствами и акциями. Предприятия лесопереработки стали собственниками лесхозов.

В ряде отраслей в силу очевидного шока на первых этапах реформ центром консолидации стало не производство, а поставка сырья или сбыт готовой продукции. Легкая промышленность предсказуемо консолидировалась вокруг торговцев хлопком, сформировав достаточно крупные холдинги (ОАО «Альянс «Русский Текстиль») Парфюмерно-косметическая промышленность также формировалась в направлении вертикальной интеграции («Концерн Калина» до недавнего времени владел производством туб для зубной пасты) [6].

Некоторые отрасли укрупнялись горизонтально. Наиболее типичный пример пищевая промышленность, в которой крупные компании сформировались естественным путем, постепенно скупая региональные предприятия и встраивая их продукт в общенациональную систему торговых марок. По такому пути создавались компании «Вимм-Билль-Данн» и «Балтика».

Большинство перечисленных компаний закономерно стали привлекательными для приобретения крупными инвесторами, в том числе и представителями международных холдингов: PepsiCo, Coca-Cola, Unilever.

Описанные и наглядно подтвердившиеся в историческом разрезе примеры повторяются и в текущей ситуации в ряде отраслей, которые по специфическим причинам не вошли в контур первой консолидации промышленности: в основном речь идет о машиностроении, оборонной промышленности, строительном секторе, рынке грузоперевозок, портовых и терминальных мощностях.
Инвестиционный процесс на вновь приобретенных заводах (и активах в широком понимании) вызывает потребность в привлечении капитала. Трансформируясь в интересах инвесторов, компании естественным образом приходят к необходимости перестраивать собственную систему корпоративного управления. Ресурсы, доступные для привлечения на российские рынки капитала, достаточно велики, чтобы обратить на них внимание. Суммарная капитализация всех российских компаний составляет около 600 млрд долларов, что открывает новые возможности для компаний, стремящихся к первичному размещению акций.

Долговой рынок сегодня, даже с учетом всех перечисленных ранее ограничений со стороны международных инвесторов, предоставляет возможность для заимствования порядка 6-7 млрд долларов, причем, по оценкам профильных аналитиков, в ближайшие годы эта сумма как минимум утроится за счет расширения сотрудничества с инвесторами из новых регионов (Ближний Восток, Китай, Япония), а также формирования экосистемы внутренних инвестиций.

На наш взгляд, совершенствование системы связей с инвесторами и корпоративного управления должно осуществляться по следующим направлениям:

1. Стандартизация управленческой практики на дочерних предприятиях. Среди прочего это предполагает равноправие миноритарных акционеров дочерних предприятий, прозрачную систему закупок, использование трансфертных цен только в случае согласия миноритарных совладельцев с этой стратегией и при наличии альтернатив для них.

2. Решение проблем консолидации отчетности по международным стандартам отечественными компаниями. Инвесторы получают возможность видеть фактические (а не мнимые) финансовые потоки внутри компании, а главное - сопоставлять их с аналогами, в том числе и международными. Предполагаемая модель отчет- 
ности может включать следующие элементы: отдельная, совместимая, консолидированная и интегрированная отчетности [8]. Это актуально как для крупных корпораций, так и для среднего бизнеса.

3. Регулярная отчетность - принципиальный вопрос для инвесторов, поскольку ежегодный отчет по МСФО является слишком редким, чтобы служить хорошим индикатором изменения климата в компании.

4. Принятие кодекса корпоративного управления. В этом документе традиционно освещаются вопросы, связанные с дивидендной политикой, стратегией развития компании и отношениями с акционерами, практикой новых приобретений и консолидацией дочерних предприятий, участием в правовых спорах и принципами конкурентной борьбы.

5. Участие независимых директоров $b$ управлении компанией либо расширение их присутствия. Речь идет о профессионалах, принимающих участие в комитетах, которые проводят внутренний аудит, разрешают корпоративные конфликты, принимают решения о вознаграждении. На уро- вень качества корпоративного управления напрямую влияет количество независимых директоров. Отношение независимых директоров к общему составу наблюдательного совета должно составлять $25 \%$. Как бы то ни было, в составе совета должно быть не менее трех независимых директоров, информацию о которых должен содержать годовой отчет АО.

6. Максимальные усилия по повышению миквидности собственных ценных бумаг. Крупная компания может позволить себе листинг на международных биржах, мелкая - наем брокера для установления стабильных двусторонних котировок на российском рынке.

Дальнейшее совершенствование системы корпоративного управления - необходимое условие повышения инвестиционной привлекательности российских компаний, что уже доказали своими примерами компании «МТС», «Вымпелком» (ныне VEON), ПАО «ФосАгро», ПАО «НОВАТЭК» и около пяти десятков небольших компаний, привлекающих долгосрочные кредитные ресурсы на рынке облигаций.

\section{Список литературы}

1. Бендиков М. А., Колесник Г. В. Оценка инвестиционной стоимости инструментов корпоративного контроля в системах с распределенными правами собственности // Стратегическое планирование и развитие предприятий : материалы Пятнадцатого всероссийского симпозиума / под ред. Г. Б. Клейнера. - М. : ЦЭМИ РАН, 2014. - С. 28-32.

2. Гусаков В. А. Принципы корпоративного управления: стандарт для бизнеса ЕАЭС и выгода для государства // Сотрудничество государств-членов ЕАЭС с ОЭСР в контексте развития интеграционной повестки Союза. Возможности использования наилучших практик ОЭСР в работе ЕАЭС. - М. : Евразийская экономическая комиссия, 2017. - С. 56-58.

3. Завьялова Е. Б., Кондратьева В. Б. Корпоративное управление как фактор повышения инвестиционной привлекательности : коллективная монография. - М. : МГИМО, 2014.

4. Колесник Г. В. Информационная асимметрия агентов в моделях корпоративных систем с распределенными правами собственности // Финансовая аналитика: проблемы и решения. - 2012. - № 9 (99). - С. 34-40.

5. Колесник Г. В. Моделирование формирования инвестиционной стоимости инструментов корпоративного контроля // Экономика и математические методы. - 2010. T. 46. - № 3. - C. 93-100. 
6. Лозик Н. Ф. Конкурентоспособность корпоративных хозяйственных систем : дис. ... канд. экон. наук. - М., 2000.

7. Меркулина И. А. Структура экономического обоснования инвестиций в топливноэнергетические компании / / Экономика и управление в машиностроении. - 2018. - № 4. C. 27-29.

8. Сигидов Ю. И., Настенко Д. А. Актуальные проблемы реформирования консолидированной финансовой отчетности // Международный бухгалтерский учет. - 2013. № 9 (255). - С. 2-13.

9. Царегородиељ Д. В. Российская нефтяная промышленность: итоги 2001 года и перспективы / / Рынок ценных бумаг. - 2002. - № 5. - С. 1-7.

\section{References}

1. Bendikov M. A., Kolesnik G. V. Otsenka investitsionnoy stoimosti instrumentov korporativnogo kontrolya $\mathrm{v}$ sistemakh s raspredelennymi pravami sobstvennosti [Estimating the Investment Value of Tools of Corporate Control in Systems of Distributed Property Rights]. Strategicheskoe planirovanie $i$ razvitie predpriyatiy, materialy Pyatnadtsatogo vserossiyskogo simpoziuma [Strategic Planning and Development of Enterprises. Materials of the Fifteenth all-Russian Symposium], edited by G. B. Kleyner. Moscow, CEMI RAS, 2014, pp. 28-32. (In Russ.).

2. Gusakov V. A. Printsipy korporativnogo upravleniya: standart dlya biznesa EAES i vygoda dlya gosudarstva [Principles of Corporate Management: Standard for EAEU Business and Advantages for State]. Sotrudnichestvo gosudarstv-chlenov EAES s OESR v kontekste razvitiya integratsionnoy povestki Soyuza. Vozmozhnosti ispolzovaniya nailuchshikh praktik OESR v rabote EAES [Cooperation of EAEU Member States with OESR in View of Developing the Integration Agenda of the Union. Opportunities to use the best OESR practices in EAEU work]. Moscow, Evraziyskaya ekonomicheskaya komissiya, 2017. (In Russ.).

3. Zavyalova E. B., Kondrateva V. B. Korporativnoe upravlenie kak faktor povysheniya investitsionnoy privlekatelnosti, kollektivnaya monografiya [Corporate Management as a Factor of Raising Investment Appeal, joint monograph]. Moscow, MGIMO, 2014. (In Russ.).

4. Kolesnik G. V. Informatsionnaya asimmetriya agentov $\mathrm{v}$ modelyakh korporativnykh sistem s raspredelennymi pravami sobstvennosti [Information Agent Asymmetry in Models of Corporate Systems with Distributed Property Rights]. Finansovaya analitika: problemy i resheniya [Finance Analysis: Problems and Solutions], 2012, No. 9 (99), pp. 34-40. (In Russ.).

5. Kolesnik G. V. Modelirovanie formirovaniya investitsionnoy stoimosti instrumentov korporativnogo kontrolya [Modeling the Process of Shaping Investment Value of Tools for Corporate Control]. Ekonomika i matematicheskie metody [Economics and Mathematic Methods], 2010, Vol. 46, No. 3, pp. 93-100. (In Russ.).

6. Lozik N. F. Konkurentosposobnost korporativnykh khozyaystvennykh system. Diss. kand. ekon. nauk [Competitiveness of Corporate Economic Systems. PhD econ. sci. diss.]. Moscow, 2000. (In Russ.).

7. Merkulina I. A. Ctruktura ekonomicheskogo obosnovaniya investitsiy v toplivnoenergeticheskie kompanii [The Structure of Economic Substantiation of Investment into Fuel 
and Power Companies]. Ekonomika $i$ upravlenie $v$ mashinostroenii [Economics and Management in Machine-Building], 2018, No. 4, pp. 27-29. (In Russ.).

8. Sigidov Yu. I., Nastenko D. A. Aktualnye problemy reformirovaniya konsolidirovannoy finansovoy otchetnosti [Acute Issues in Reforming Consolidated Finance Accounting]. Mezhdunarodnyy bukhgalterskiy uchet [International Accounting], 2013, No. 9 (255), pp. 2-13. (In Russ.).

9. Tsaregorodtsev D. V. Rossiyskaya neftyanaya promyshlennost: itogi 2001 goda i perspektivy [Russian Oil Industry: Results of 2001 and Prospects]. Rynok tsennykh bumag [Securities Market], 2002, No. 5, pp. 1-7. (In Russ.).

\section{Сведения об авторах}

\section{Нина Федоровна Лозик}

кандидат экономических наук, доцент кафедры «Финансы и кредит»

НАНО ВО «ИМЦ».

Адрес: НАНО ВО «Институт мировых цивилизаций», 119049, Москва,

Ленинский проспект, д. 1/2, корп. 1.

E-mail: loziknina@yandex.ru

\section{Александр Юрьевич Анисимов}

кандидат экономических наук, доцент

кафедры «Финансы и кредит»

НАНО ВО «ИМЦ».

Адрес: НАНО ВО «Институт мировых цивилизаций», 119049, Москва,

Ленинский проспект, д. 1/2, корп. 1.

E-mail: anisimov_au@mail.ru

\section{Артур Анатольевич Панасюк}

кандидат экономических наук, заведующий

кафедрой «Финансы и кредит»

НАНО ВО «ИМЦ».

Адрес: НАНО ВО «Институт мировых цивилизаций», 119049, Москва,

Ленинский проспект, д. 1/2, корп. 1.

E-mail:_panas@rambler.ru

\section{Information about the authors}

Nina F. Lozik

PhD, Assistant Professor

of the Department for «Finance and Credit» of the IWC.

Address: Institute of World Civilizations, 1 building, 1/2 Leninsky Avenue, Moscow, 119049, Russian Federation.

E-mail: loziknina@yandex.ru

\section{Alexander Yu. Anishimov}

$\mathrm{PhD}$, Assistant Professor

of the Department for «Finance and Credit» of the IWC.

Address: Institute of World Civilizations,

1 building, 1/2 Leninsky Avenue,

Moscow, 119049, Russian Federation.

E-mail: anisimov_au@mail.ru

\section{Arthur A. Panasyuk}

PhD, the Head of the Department

for «Finance and Credit»

of the IWC.

Address: Institute of World Civilizations,

1 building, 1/2 Leninsky Avenue,

Moscow, 119049, Russian Federation.

E-mail:_panas@rambler.ru 